
transplantation in allogeneic hematopoietic stem cell transplantation patients

\title{
Morishita $\mathrm{S}^{1.2}$, Tanaka $\mathrm{T}^{3}$, Wakasugi $\mathrm{T}^{3}$, Harada $\mathrm{T}^{3}$, Kaida $\mathrm{K}^{4}$, Ikegame $\mathrm{K}^{4}$, Ogawa $\mathrm{H}^{4}$, and Domen $\mathrm{K}^{2}$
}

1 Institute for Human Movement and Medical Science Niigata University of Health and Welfare

2 Department of Rehabilitation Medicine, Hyogo College of Medicine

3 Department of Physical Medicine and Rehabilitation, Hyogo College of Medicine Hospital

4 Division of Hematology, Department of Internal Medicine, Hyogo College of Medicine

\section{Background and aims}

- We analyzed the results of the exercise-tolerance test performed before and after transplantation, in patients who had undergone allogeneic hematopoietic stem cell transplantation (allo-HSCT)

- Furthermore, we investigated the relationship between Heart Rate (HR), Borg scale, and exercise-tolerance watts in allo-HSCT patients before and after transplantation.

\section{Methods}

1. Exercise tolerance test

$(\mathrm{W})$

60$$
40
$$$$
20
$$$$
\begin{array}{lllllllllll}
0 & 1 & 2 & 3 & 4 & 5 & 6 & 7 & 8 & 9 & 10 \\
(\mathrm{~min})
\end{array}
$$

\section{Measurement period}

Befor

-2 week

Measurement HSCT

Patients were instructed to maintain a speed of 50-60 rotations per minute (rpm)

If a patient could not main at least $50 \mathrm{rpm}$, the exercise tolerance test was discontinued.
Results 1. Watts, HR, and Borg scale at the end of the exercise tolerance test, before and after HSCT.
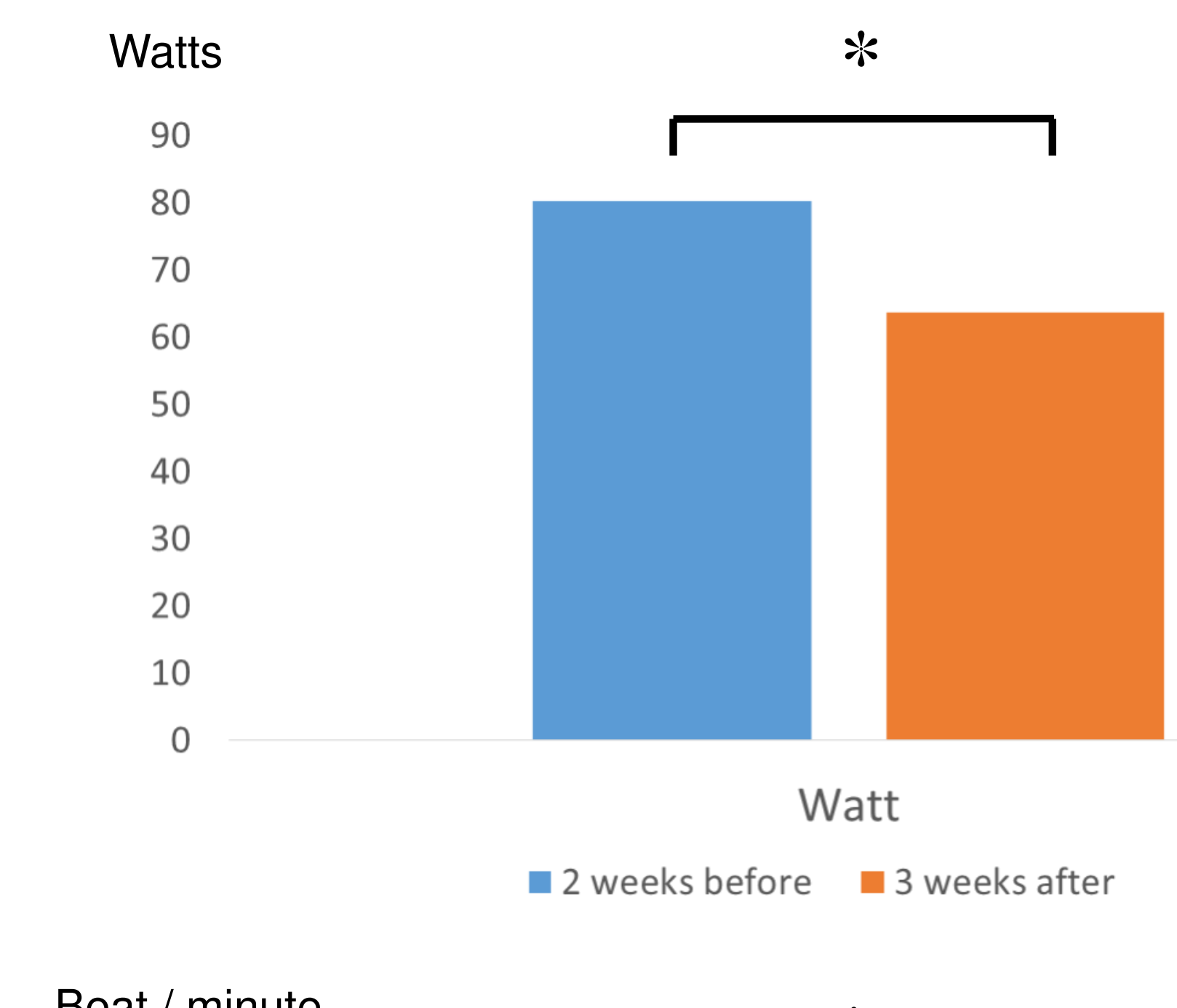

Watt

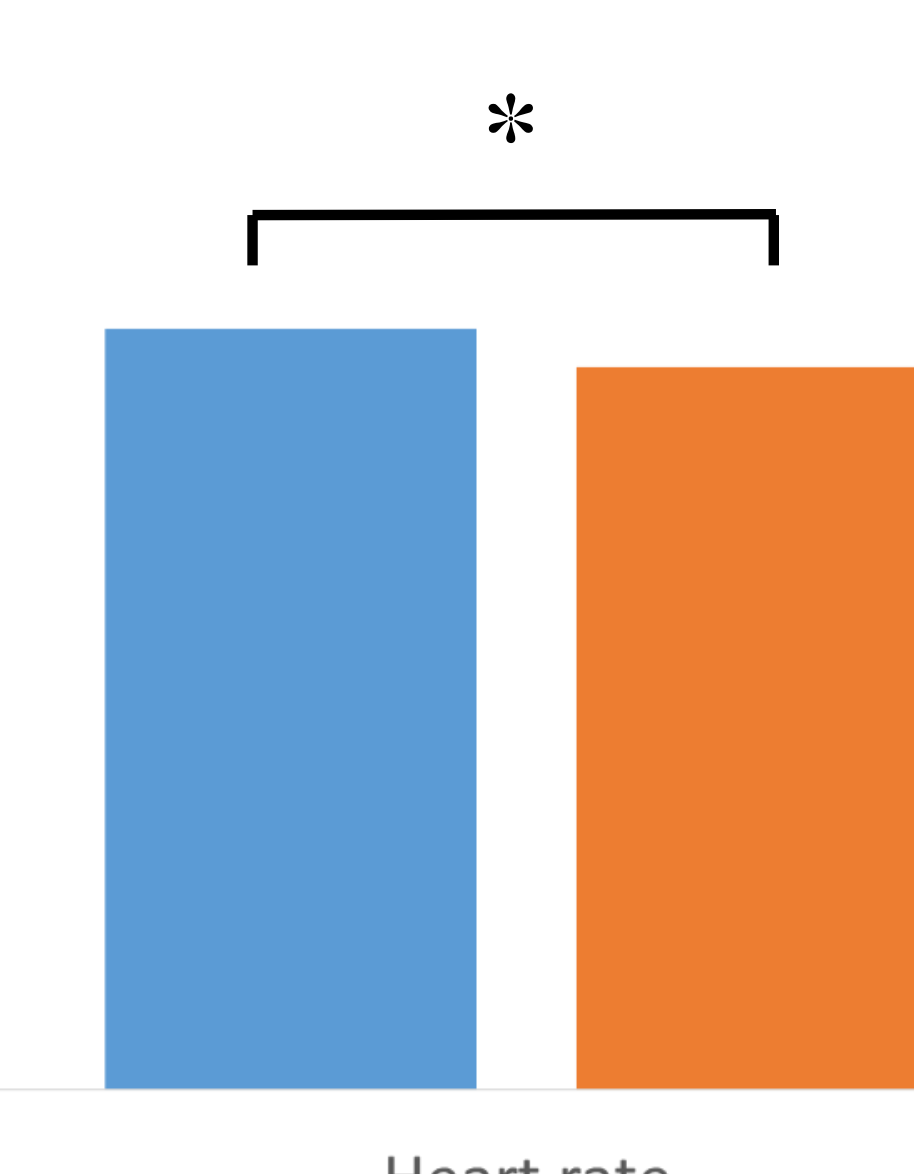$$
\text { (1) }
$$

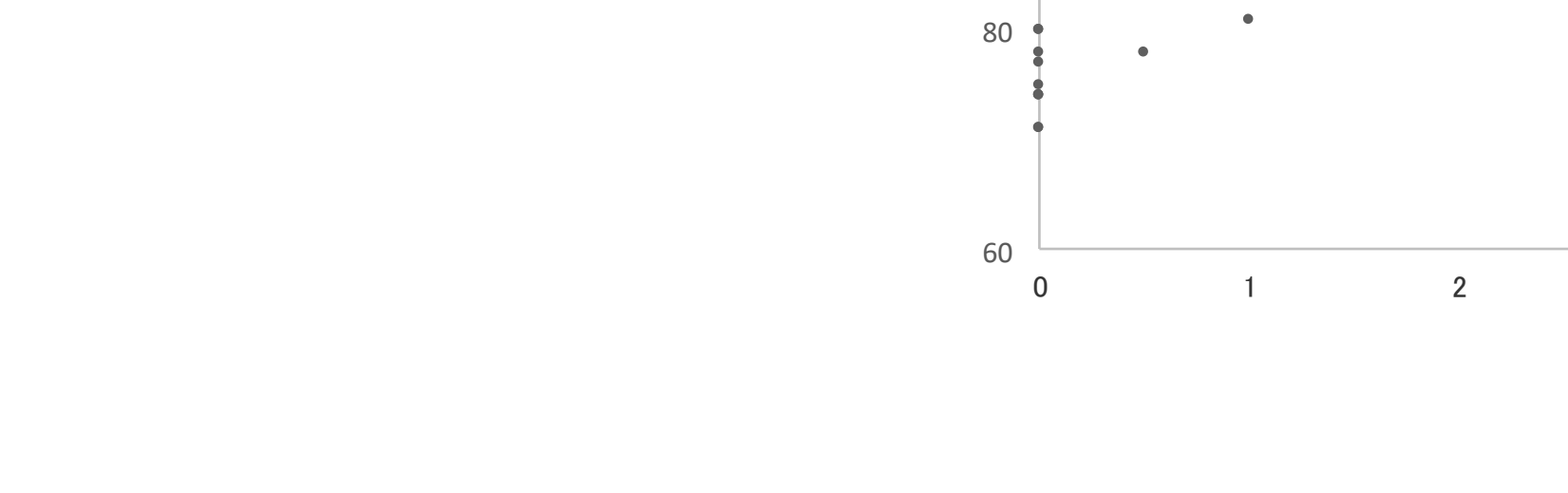

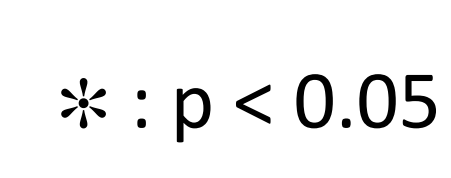

before HSCT

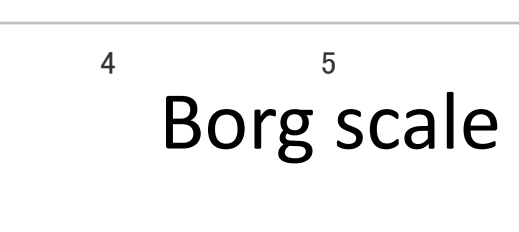

After

+3 week Measurement $\Rightarrow$

\section{Results} test before and after HSCT.

\begin{tabular}{|c|c|c|}
\hline \multicolumn{3}{|c|}{ Participants } \\
\hline \multicolumn{3}{|l|}{ Characteristics } \\
\hline Age & & $41.5(18-60)$ \\
\hline \multirow[t]{2}{*}{ Sex } & Men & $19(67.9)$ \\
\hline & Women & $9(32.1)$ \\
\hline Height (cm) & & $166.2(9.5)$ \\
\hline Body weight (kg) & & $59.5(15.3)$ \\
\hline \multirow{3}{*}{ Diagnosis } & Acute leukaemia & $18(64.3)$ \\
\hline & Malignant lymphoma & $6(21.4)$ \\
\hline & $\begin{array}{l}\text { Myelodysplastic } \\
\text { syndrome }\end{array}$ & $4(14.3)$ \\
\hline \multirow[t]{3}{*}{ Stem cell source } & $\begin{array}{l}\text { Peripheral blood stem } \\
\text { cell }\end{array}$ & $24(85.7)$ \\
\hline & Bone marrow & $2(7.1)$ \\
\hline & Cord blood & $2(7.1)$ \\
\hline \multirow[t]{4}{*}{ Donor } & HLA-matched/related & $1(3.6)$ \\
\hline & $\begin{array}{l}\text { HLA- } \\
\text { matched/unrelated }\end{array}$ & $1(3.6)$ \\
\hline & $\begin{array}{l}\text { HLA- } \\
\text { mismatched/related }\end{array}$ & $24(85.7)$ \\
\hline & $\begin{array}{l}\text { HLA- } \\
\text { mismatched/unrelated }\end{array}$ & $2(7.1)$ \\
\hline \multirow[t]{2}{*}{ Conditioning } & Myeloabalative & $3(10.7)$ \\
\hline & Reduced intensity & $25(89.3)$ \\
\hline
\end{tabular}

\section{Measurement}

We evaluated the watts, heart rate, and Borg scale at the end of the exercise tolerance test, before and after HSCT.

We asked the patients and recorded their responses on the Borg scale, and also evaluated $\mathrm{HR}$ every minute during the exercise tolerance test.

\begin{tabular}{cl}
\hline Rating & Descriptor \\
\hline 0 & Rest \\
1 & Very, very easy \\
2 & Easy \\
3 & Moderate \\
4 & Somewhat hard \\
5 & Hard \\
6 & - \\
7 & Very hard \\
8 & - \\
9 & - \\
10 & Maximal \\
\hline Borg Category Ratio (Borg CR-
\end{tabular}

10)
Results 2. Relationships between Borg scale and heart rate, and watts during exercise tolerance

before HSCT after HSCT

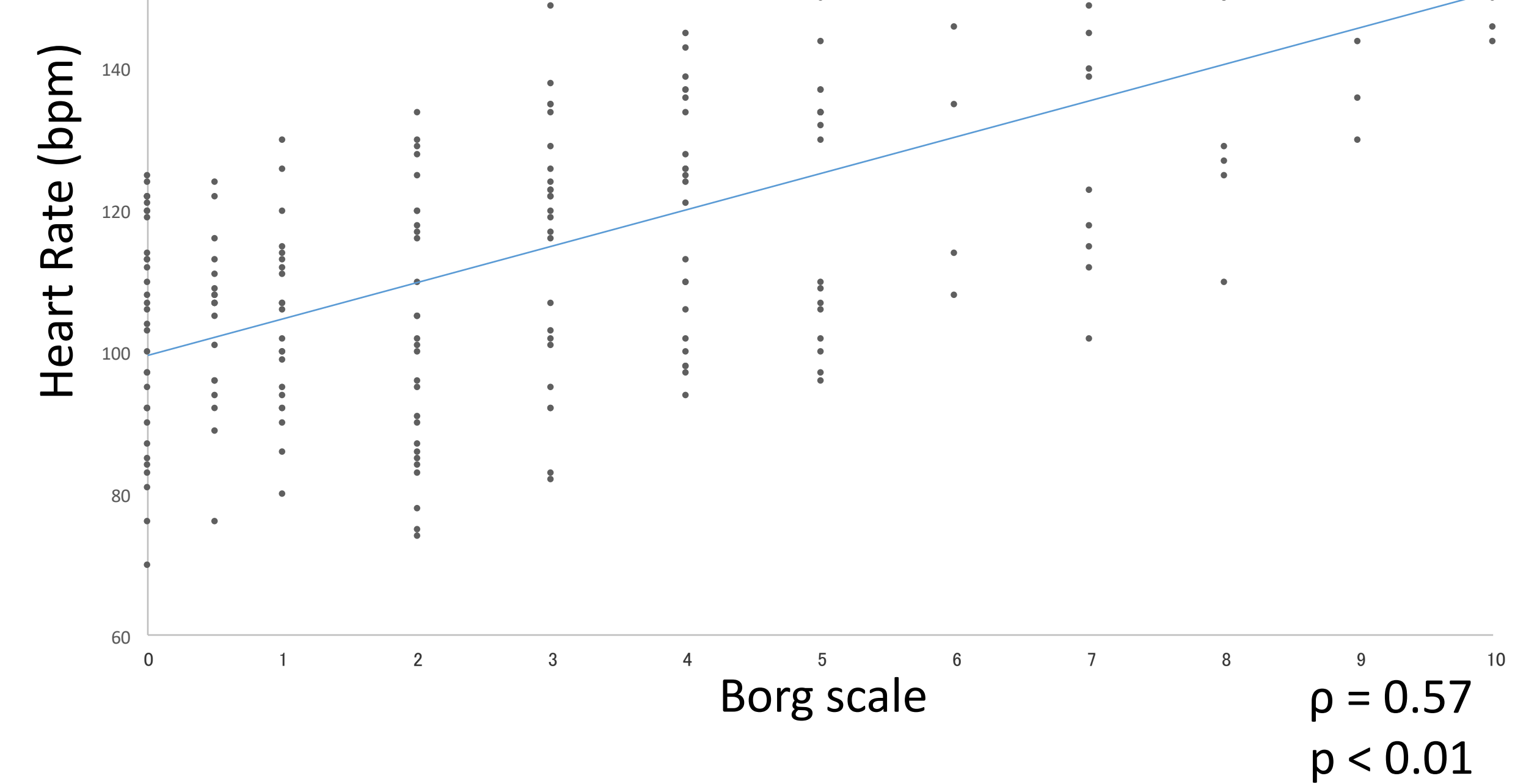

after HSCT

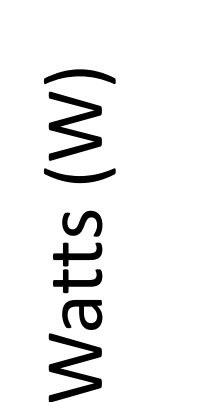

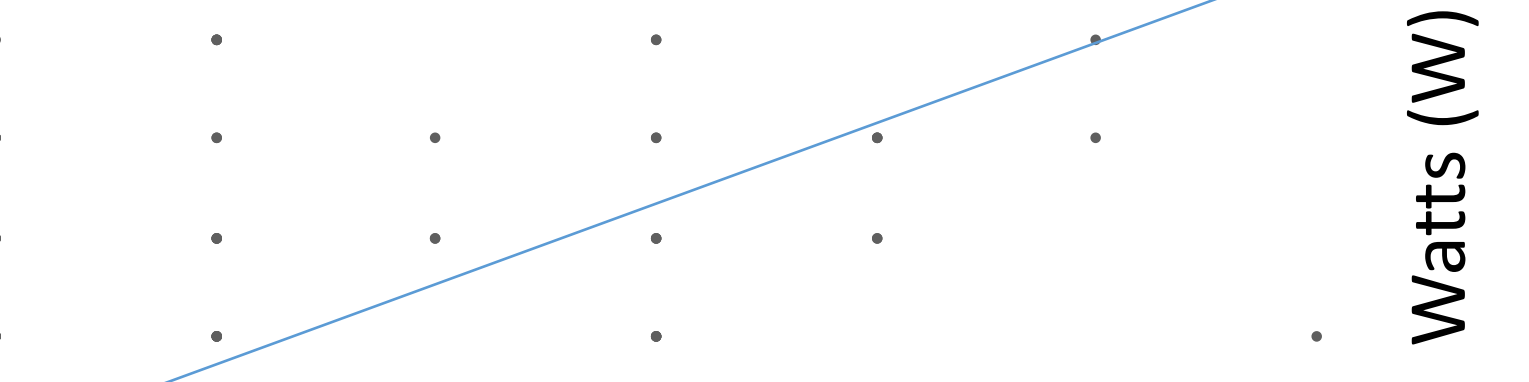

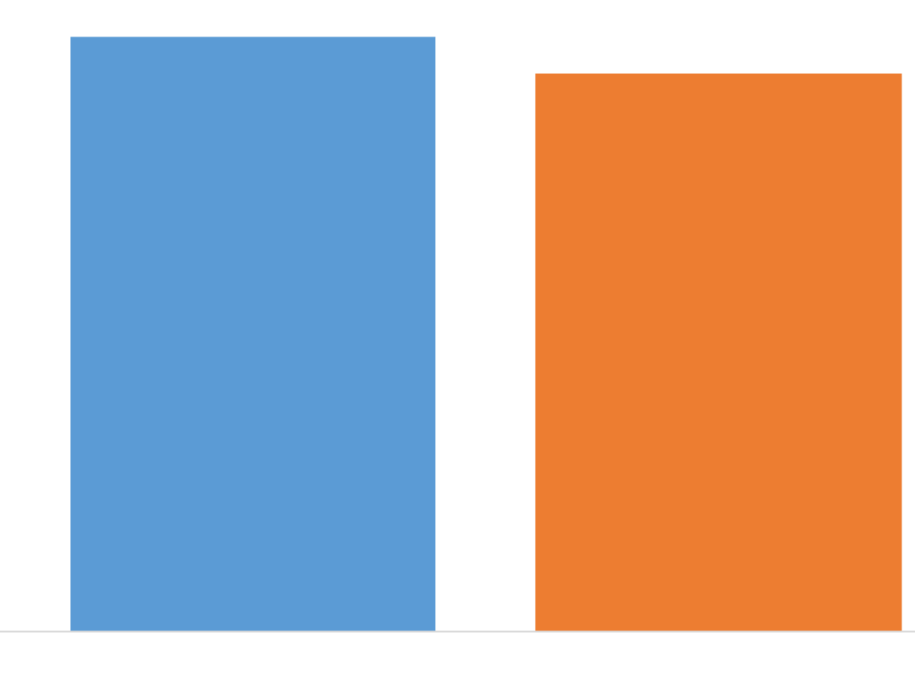

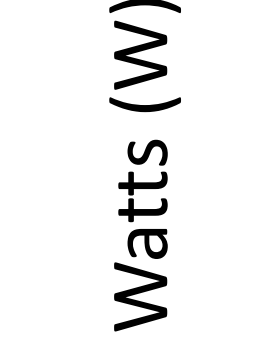

Borg scale

\section{Conclusions}

- A correlation was found between Borg scale with intensity of exercise tolerance in patients who had undergone allo-HSCT

- Borg scale could be useful to determine the intensity of physical exercise in patients who have undergone allo-HSCT. 